\title{
Lipid Profile Level among Healthy Subjects and Their Relation with Obesity- A Clinical Study
}

\author{
Radhika Muttath ${ }^{\circledR 1}$, Vinu Thomas ${ }^{\circledR 2}$ \\ ${ }^{1}$ Associate Professor, Department of Medicine, Government Medical College, Thrissur, Kerala, India, 2Professor, Department of Medicine, Government Medical College, \\ Thrissur, Kerala, India.
}

\section{Abstract}

Background: Obesity is a common metabolic disease world-wide and dyslipidemias among the most common metabolic disorders associated with obesity. The present study was undertaken to assess lipid profile level among healthy subjects and their relation with obesity. Subjects and Methods: This cross sectional study was conducted on 100 subjects. General information related to data such as name, age, gender etc. was recorded in case history proforma. BMI was evaluated based on formula of BMI $=$ Weight $(\mathrm{kg}) / \mathrm{Height}(\mathrm{m})^{2}$. Based on BMI, subjects were divided into two groups according to their BMI values as- group I- Obese and Group II- Non obese. Group I had 65 and group II had 35 subjects. Lipid profile was done. Results: There was significant difference in group I and group II regarding waist circumference (WC), BMI (kg/m2), body adiposity index (BAI), visceral adiposity index (VAI), total cholesterol (TC) $(\mathrm{P}<0.05)$. Waist-to-hip ratio (WHR), waist-to-height ratio (WHtR), HDL- C, LDL- C, TG, TC/HDL- C, LDL-C/HDL-C and TG/HDL-C was non- significant $(\mathrm{P}<0.05)$. There was negative correlations between BMI and TC, LDL-C, HDL-C; WC, WHR, VAI and HDL-C and positive significant correlations were found between WC, WHR, and TG/HDL-C, as well as between VAI and TC, TG, TC/HDL-C, LDL/HDL-C, and TG/ HDL-C. Conclusion: Authors found that there was alteration of lipid profile in obese subjects. VAI is strongly related with lipid profile and may be considered as reliable obesity index in obese patients with dyslipidemias.

Keywords: Dyslipidemias, Lipid profile, Obese

Corresponding Author: Vinu Thomas, Professor, Department of Medicine, Government Medical College, Thrissur, Kerala, India. E-mail: vinut6@gmail.com

Received: 4 April 2020

Revised: 7 May 2020

Accepted: 18 May 2020

Published: 10 June 2020

\section{Introduction}

Human body requires lipids such as cholesterol, triglycerides and fatty acids. In condition of dyslipidemia there is derangement of plasma lipids and their normal levels. ${ }^{[1]}$ It has been observed that dyslipidemia is considered to be the cause of atherosclerosis resulting in conditions like leading to cerebrovascular disease (CVD), coronary heart disease and peripheral vascular disease. Even it is suggested that stress level in work place is the leading cause of cardiovascular disease though pathophysiological mechanisms remain unclear for their association. ${ }^{[2]}$ The process of atherosclerosis starts in childhood and risk parameters such as dyslipidemia, positive family history, obesity, high blood pressure and diet play an important role in progression of CVD. ${ }^{[3]}$

There have been rise in cases of obesity and overweight in last few years and it is more prevalent in developing countries. World Health Organization estimated that in year 2008 , there were $>1.4$ billion overweight adults and out of these, approximately 200 million men and 300 million women were obese. ${ }^{[4]}$

It has been found that central excess adipose tissue is linked with high cardiovascular morbidity and mortality. Various methods have been used to evaluate the amount and the distribution of body fat and its correlation to CVD. Assessment of body mass index (BMI), waist circumference (WC) and waist-to-hip ratio (WHR) helps in diagnosis of obesity. ${ }^{[5]}$

Obesity is a common metabolic disease world-wide and dyslipidemias among the most common metabolic disorders associated with obesity. Obesity is often described by classical parameters such as body mass index (BMI), waist circumference (WC), and waist-to-hip ratio (WHR). Some authors indicate relationships between these obesity parameters and lipid profile. Results of meta-regression analysis of prospective, randomized studies showed that WHR and WC may play important roles in assessment of increased risk of cardiovascular (CV) events. Some studies showed that there is a signif- 
icant correlation between anthropometric variables and lipid parameters. ${ }^{[6]}$ Considering this, the present study was undertaken to assess lipid profile level among healthy subjects and their relation with obesity.

\section{Subjects and Methods}

This cross sectional study was conducted on 100 subjects in department of general medicine. The study was conducted after approval from institutional ethical committee. Patients were informed about the study procedure and written informed consent was taken.

General information related to data such as name, age, gender etc. was recorded in case history proforma. A through clinical and physical examination was performed. Weight of all subjects was measured in weighing machine in kilograms and height was measured using measuring tape.

BMI was evaluated based on formula of BMI = Weight $(\mathrm{kg}) /$ Height $(\mathrm{m}){ }^{2}$ Normal values for BMI was as followsunder weight- $<18.5$, normal weight- $18.5-24.9$, over weight25-29.9 and obesity- $>30$. Based on BMI, subjects were divided into two groups according to their BMI values asgroup I- Obese and Group II- Non obese. Group I had 65 and group II had 35 subjects.

$5 \mathrm{ml}$ of venous blood was drawn from all subjects and was transferred to new plain screw capped disposable plastic tubes. The blood sample was centrifuged for the serum separation. Centrifuge was done for 10 minutes at $1000 \mathrm{rpm}$. Blood lipid standard values were categorized according to National Cholesterol Education Program (NCEP) Guidelines. ${ }^{[6]}$

\begin{tabular}{ll}
\hline Table 1: NCEP Risk Guidelines & \\
\hline Variable & NCEP Risk Guidelines \\
LDL & $>100 \mathrm{mg} / \mathrm{dl}$ \\
HDL-C & $<50 \mathrm{mg} / \mathrm{dl}$ \\
Risk Ratio & $>3.5$ \\
Total Cholesterol & $>200 \mathrm{mg} / \mathrm{dl}$ \\
Triglycerides & $>150 \mathrm{mg} / \mathrm{dl}$ \\
\hline
\end{tabular}

The data was collected systematically and analyzed statistically according to the standard statistical methods. $P$ value less than 0.05 was considered significant.

\section{Results}

Table 1 shows that mean age in group I was 56.4 years and in group II was 58.2 years. Ischemic heart disease was seen in 21 in group I and 6 in group II, myocardial infarction in 8 in group I and 1 in group II and heart failure seen 4 in group I.

\begin{tabular}{llll}
\hline \multicolumn{4}{l}{ Table 2: Clinical characteristics of patients } \\
\hline Parameters & Group I & Group II & P-value \\
Mean age & 56.4 & 58.2 & 0.91 \\
Hypertension & 21 & 6 & 0.05 \\
IHD & 7 & 2 & 0.02 \\
MI & 8 & 1 & 0.04 \\
Heart failure & 4 & 0 & 0.12 \\
\hline
\end{tabular}

\begin{tabular}{llll}
\hline \multicolumn{4}{c}{ Table 3: Obesity and lipids parameters in the patients' groups } \\
\hline \multicolumn{1}{|c|}{ Parameters } & Group I & Group II & P value \\
\hline WC $(\mathrm{cm})$ & 124.5 & 102.5 & 0.01 \\
\hline WHR & 0.95 & 0.94 & 0.95 \\
WHtR & 0.75 & 0.62 & 0.17 \\
BMI & 42.5 & 32.7 & 0.05 \\
$\left(\mathrm{~kg} / \mathrm{m}^{2}\right)$ & & & \\
BAI & 46.2 & 33.2 & 0.02 \\
VAI & 2.3 & 1.8 & 0.05 \\
TC & 5.1 & 6.2 & 0.05 \\
HDL- C & 1.3 & 1.4 & 0.91 \\
LDL- C & 2.8 & 3.7 & 0.82 \\
TG & 1.8 & 1.7 & 0.67 \\
TC/HDL- C & 4.1 & 4.4 & 0.93 \\
LDL- & 2.4 & 2.8 & 0.92 \\
C/HDL-C & & & \\
TG/HDL-C & 1.3 & 1.2 & 0.97 \\
\hline
\end{tabular}

Table 2, Figure 1 shows there was significant difference in group I and group II regarding waist circumference (WC), BMI $(\mathrm{kg} / \mathrm{m} 2)$, body adiposity index (BAI), visceral adiposity index (VAI), total cholesterol (TC) $(\mathrm{P}<0.05)$. Waist-to-hip ratio (WHR), waist-to-height ratio (WHtR), HDL- C, LDL- C, TG, TC/HDL- C, LDL-C/HDL-C and TG/HDL-C was nonsignificant $(\mathrm{P}<0.05)$.

Table 3 shows that there was negative correlations between BMI and TC, LDL-C, HDL-C; WC, WHR, VAI and HDL-C and positive significant correlations were found between WC, WHR, and TG/HDL-C, as well as between VAI and: TC, TG, TC/HDL-C, LDL/HDL-C, and TG/ HDL-C.

\section{Discussion}

Obesity is defined as an excess accumulation of fat in the body resulting in adverse effects on health of the individual. Obesity is now estimated to be the second leading cause of mortality and morbidity, causing an estimated 2.6 million deaths worldwide and $2.3 \%$ of the global burden of disease. ${ }^{[7]}$ There is an overall consensus that obesity poses a significant 


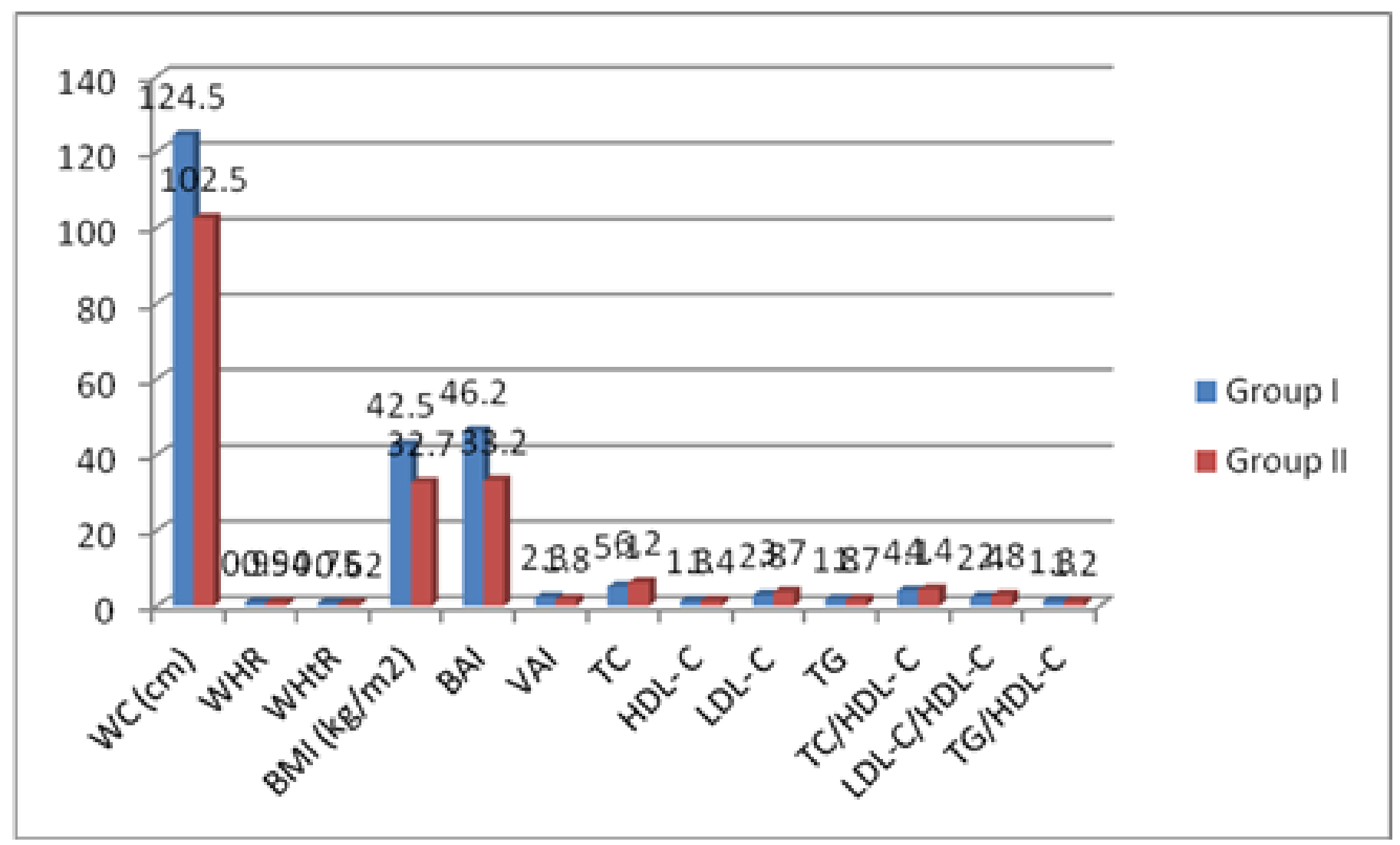

Figure 1: Obesity and lipids parameters in the patients' groups

Table 4: Correlation coefficients between lipid measurements and obesity indices

\begin{tabular}{llllllll}
\hline Indices & TC & LDL- C & HDL- C & TG & $\begin{array}{l}\text { TC/HDL- } \\
\text { C }\end{array}$ & $\begin{array}{l}\text { LDL- } \\
\text { C/HDL-C }\end{array}$ & TG/HDL-C \\
BMI & -0.22 & -0.310 & -0.30 & 0.06 & -0.05 & -0.15 & 0.172 \\
WC & -0.21 & -0.201 & -0.32 & 0.131 & 0.091 & 0.042 & 0.279 \\
WHR & -0.04 & -0.01 & -0.29 & 0.134 & 0.174 & 0.151 & 0.244 \\
WHtR & -0.17 & -0.12 & -0.10 & 0.05 & -0.07 & -0.03 & 0.113 \\
BAI & -0.05 & -0.107 & 0.170 & -0.05 & -0.18 & -0.12 & -0.01 \\
VAI & 0.32 & 0.212 & -0.37 & 0.88 & 0.618 & 0.48 & 0.927 \\
\hline
\end{tabular}

risk for the development of cardiovascular disease, alterations in glucose metabolism and reduces life expectancy. Lipids and lipoproteins are well known risk factors for ischemic heart disease. Elevated levels of triglyceride, cholesterol and LDL$\mathrm{C}$ are documented as risk factors for atherogenesis. LDL-C in its oxidized or acetylated form has been identified as a major atherogenic particle; as it not only load macrophages with cholesterol for the formation of foam cells but also because it is chemotactic for circulating monocytes, is cytotoxic and can adversely alter coagulation pathways. ${ }^{[8]}$
New obesity indices (e.g., waist-to-height ratio (WHtR), visceral adiposity index (VAI), and body adiposity index (BAI) take into account adipose tissue distribution. Results of the some recently published studies suggest that WHtR, the newer obesity index, may be helpful for assessing risk of metabolic complications, including dyslipidemia, and it may also be a predictor of cardiovascular events in obese patients. Nevertheless, there is little data about the associations between other newer obesity indices (e.g., VAI and BAI) and lipid profile in obese patients. ${ }^{[9]}$ The present study was undertaken to assess lipid profile level among healthy subjects and their 
relation with obesity.

In this study, mean age in group I was 56.4 years and in group II was 58.2 years. Ischemic heart disease was seen in 21 in group I and 6 in group II, myocardial infarction in 8 in group I and 1 in group II and heart failure seen 4 in group I. Sharmai et al, ${ }^{[10]}$ determined association of body mass index and lipid profiles in 637 patients out of which 362 were females. Authors found that higher BMI was inversely associated with HDL and directly associated with TG. BMI showed no significant association with LDL. There was no association between higher BMI and LDL, a negative association with high-density lipoprotein cholesterol and a positive association with the log transformation of triglycerides. Suneetha $K,{ }^{[11]}$ found similar results.

We found that there was significant difference in group I and group II regarding waist circumference (WC), BMI $(\mathrm{kg} / \mathrm{m} 2)$, body adiposity index (BAI), visceral adiposity index (VAI), total cholesterol (TC) $(\mathrm{P}<0.05)$. Waist-to-hip ratio (WHR), waist-to-height ratio (WHtR), HDL- C, LDL- C, TG, TC/HDL- C, LDL-C/HDL-C and TG/HDL-C was nonsignificant. There was negative correlations between BMI and TC, LDL-C, HDL-C; WC, WHR, VAI and HDL-C and positive significant correlations were found between $\mathrm{WC}$, WHR, and TG/HDL-C, as well as between VAI and: TC, TG, TC/HDL-C, LDL/HDL-C, and TG/ HDL-C. Manjareeka et al, ${ }^{[12]}$ in their study assessed correlation of anthropometry and lipid profile in healthy subjects. They included 1187 subjects of both genders and their height, weight, waist circumference (WC), and hip circumference was measured. In all subjects, blood sample was obtained and lipid profile level was evaluated. Authors found weak correlation between body mass index (BMI) and lipid parameters.

Al-Agha et al (2019), ${ }^{[13]}$ conducted a study to assess the relationship between lipid profile components among different body mass index (BMI) groups. They included 218 children and adolescents of which 104 were males and 114 were females. It was found that $10.6 \%$ of subjects were overweight; $22.1 \%$ had obesity, out of which $7.1 \%$ were morbidly obese. It was further observed that children who had high levels of low-density lipoprotein (LDL) and low levels of high-density lipoprotein (HDL) had higher BMI groups, with elevated cholesterol levels noted in patients of increased weight. $71 \%$ of the children had increase in HDL levels who avoided fast-food consumption. There was no significant correlation of BMI and gender.

Being overweight or obese can lead to adverse metabolic effects on, cholesterol and triglycerides. Free fatty acids (FFA) are released in abundance from adipose tissue mass. As a consequence, FFA increases the liver production of TG and secretion of VLDL. Hypertriglyceridaemia and VLDL reduce HDL cholesterol. Circulating FFA, may contribute to the induction of hypertension. ${ }^{[14]}$

\section{Conclusion}

Authors found that there was alteration of lipid profile in obese subjects. VAI is strongly related with lipid profile and may be considered as reliable obesity index in obese patients with dyslipidemias.

\section{References}

1. Kwiterovich PO. Recognition and management of dyslipidemia in children and adolescents. J Clin Endocrinol Metab. 2008;93:4200-4209. Available from: https://dx.doi.org/10. 1210/jc.2008-1270.

2. Baker JL, Olsen LW, Sørensen TIA. Childhood Body-Mass Index and the Risk of Coronary Heart Disease in Adulthood. N Eng J Med. 2007;357(23):2329-2337. Available from: https: //dx.doi.org/10.1056/nejmoa072515.

3. Mokdad AH. The Continuing Epidemic of Obesity in the United States. JAMA - J Am Med Assoc. 2000;284(13):1650 1651. Available from: https://dx.doi.org/10.1001/jama.284.13. 1650.

4. Stea TH, Wandel M, Mansoor MA, Uglem S, Frolich W. BMI, lipid profile, physical fitness and smoking habits of young male adults and the association with parental education. Eur J Public Health. 2008;19(1):46-51. Available from: https://dx.doi.org/ 10.1093/eurpub/ckn122.

5. Daniels SR, and FRG. Lipid Screening and Cardiovascular Health in Childhood. Pediatrics. 2008;122(1):198-208. Available from: https://dx.doi.org/10.1542/peds.2008-1349.

6. Jellinger PS, Dickey RA, Ganda OP, Mehta AE, Nguyen TT, Rodbard HW, et al. AACE medical guidelines for clinical practice for the diagnosis and treatment of dyslipidemia and prevention of atherogenesis. Endocr Pract. 2000;6(2):162-213.

7. Cercato C, Mancini MC, Arguello AMC, Passos VQ, Villares SMF, Halpern A. Systemic hypertension, diabetes mellitus, and dyslipidemia in relation to body mass index: evaluation of a Brazilian population. Revista do Hospital das Clínicas. 2004;59(3):113-118. Available from: https://dx.doi.org/10. 1590/s0041-87812004000300004.

8. Mason C, Craig CL, Katzmarzyk PT. Influence of Central and Extremity Circumferences on All-cause Mortality in Men and Women. Obesity. 2008;16(12):2690-2695. Available from: https://dx.doi.org/10.1038/oby.2008.438.

9. Rinaldi AEM, de Oliveira EP, Moreto F, Gabriel GFCP, Corrente JE, Burini RC. Dietary intake and blood lipid profile in overweight and obese schoolchildren. BMC Res Notes. 2012;5:598-598. Available from: https://dx.doi.org/10.1186/ 1756-0500-5-598.

10. Shamai L, Lurix E, Shen M, Novaro GM, Szomstein S, Rosenthal R, et al. Association of Body Mass Index and Lipid Profiles: Evaluation of a Broad Spectrum of Body Mass Index Patients Including the Morbidly Obese. Obesity Surgery. 2011;21(1):42-47. Available from: https://dx.doi.org/10.1007/ s11695-010-0170-7. 
11. Suneetha K. Study of Lipid Profile in Obese and Non-obese Students in Acharya Nagarjuna University. Int J Pharmaceut Clin Res. 2018;10(2):40-42.

12. Manjareeka M, Nanda S, Mishra J, Mishra S. Correlation between anthropometry and lipid profile in healthy subjects of Eastern India. J Mid-life Health. 2015;6(4):164-164. Available from: https://dx.doi.org/10.4103/0976-7800.172302.

13. Al-Agha AE, Milyani AA. The effect of body mass index and gender on lipid profile in children and adolescents in Saudi Arabia. Ann Afr Med. 2019;18(1):42-46. Available from: https://dx.doi.org/10.4103/aam.aam 1718 .

14. Ugwuja EI, Ogbonna NC, Nwibo AN, Onimawo IA. Overweight and Obesity, Lipid Profile and Atherogenic Indices among Civil Servants in Abakaliki, South Eastern Nigeria. Ann Med Health Sci Res. 2013;3:13-18. Available from: https: //dx.doi.org/10.4103/2141-9248.109462.
Copyright: (C) the author(s), 2020. It is an open-access article distributed under the terms of the Creative Commons Attribution License (CC BY 4.0), which permits authors to retain ownership of the copyright for their content, and allow anyone to download, reuse, reprint, modify, distribute and/or copy the content as long as the original authors and source are cited.

How to cite this article: Muttath R, Thomas V. Lipid Profile Level among Healthy Subjects and Their Relation with ObesityA Clinical Study. Acad. J Med. 2020;3(1):42-46.

DOI: dx.doi.org/10.47008/ajm.2020.3.1.9

Source of Support: Nil, Conflict of Interest: None declared. 